\title{
Interventional Radiology: The Invisible Part of the Iceberg
}

\author{
(D) Hakan Önder ${ }^{1}$, (D) Jafar Golzarian², (D) Serkan Arıbal1, (D) Okan İnce ${ }^{1}$, (D) Eyüp Kaya ${ }^{1}$, (D) Tanju Kisbet ${ }^{1}$ \\ 1 University of Health Sciences Turkey, Prof. Dr. Cemil Taşcıoğlu City Hospital, Clinic of Radiology, Istanbul, Turkey \\ 2University of Minnesota, Deparment of Radiology, Division of Interventional Radiology and Vascular Imaging, Minneapolis, MN, USA
}

\section{Abstract}

T-Tube occlusion removal under fluoroscopy was introduced by Alexander R. Margulis in 1967 and the placement of vascular prosthesis by Dotter in 1969. Thereafter, rapid developments in minimally invasive treatment methods occurred in the field of "interventional radiology," including the dazzling developments in the vascular, non-vascular, and neurointerventional fields. Radiologists primarily receive diagnostic radiology training, thus they are very skillful in using these treatment methods. Routine procedures in most countries include biopsies, drains, angiographies, venous dialysis catheters, port placement for chemotherapy, ablative treatments, etc. Additionally, some treatment methods continue to become widespread such as temporary intracranial stents, flow-diverter stents, middle cerebral artery embolization for chronic subdural hematoma, thyroid ablation and embolization, cryoablation, chemosaturation, bariatric embolization, uterine fibroid embolization, fallopian tube recanalization, hemorrhoidal embolization, varicocele treatment, prostatic artery embolization, and geniculate artery embolization. Continuous developments in the field of new interventional radiological treatment have been improving since the writing of this review.

Keywords: Inverventional radiology, biopsy, anigography, endovascular treatment

\section{INTRODUCTION}

\section{Temporary Intracranial Stents}

Coiling with the double stent technique in intracranially located wide neck aneurysms increases the efficiency of the procedure and provides a more robust operation $(1,2)$. However, double stents may increase the occurrence of side effects. Complications have been reported in a $2-12.7 \%$ rating $(3,4)$. Thereupon, solutions to reduce the stent load were considered and temporary stents started to develop.

Temporary stents include new temporary bridging devices that are developed to cover the aneurysm neck during coiling. Comaneci device (Rapid Medical, Yokneam, Israel) (Figure 1) and PulseRider (Cerenovus, New Brunswick, NJ), as well as solitaire FR revascularization device (Medtronic), are in use. Temporary device usage instead of a second stent deployment can be a straightforward alternative in overcoming potential difficulties (5).

\section{Flow-Diverter Stents}

Flow-diverter devices (FDD) are new-generation stents that are placed in the parent artery at the aneurysm neck level to disrupt the intra-aneurysmal flow, both provide significant rheologic effects with potential changes in the transmural pressure gradient and progressively create an intra-aneurysmal thrombosis, thus offering good support for the neointima development (6).

The following are the approved five types of intracranial aneurysm treatment: Silk (Balt Extrusion, Montmorency, France), Pipeline Embolization Device (PED) (Covidien, Mansfield, MA, USA), p64 Flow-Modulation Device (Phoenix, AZ, USA), Flow Redirection Endoluminal Device (Microvention, Tustin, CA, USA), and Surpass Flow-Diverter (Surpass; Stryker Neurovascular, Fremont, CA, USA).

The PED (Chestnut Medical Technologies, Menlo Park, CA) was the first commercially available FDD. Pipeline received 
the Conformité Européene mark in June 2008 and entered the market after receiving the Food and Drug Administration approval on April 6, 2011. Since then, exponential growth has been witnessed in technological advancements in flow-diverter stent (7). In addition, modeling stents can be used to support FDDs according to the configuration of aneurysms (Figure 2).

FDDs are rapidly becoming a suitable alternative to the traditional endosaccular treatments for uncoilable aneurysms. Among all saccular aneurysms, those with large necks and low dome-toneck ratio should preferably be treated by FDDs because they respond less favorably to other treatments.

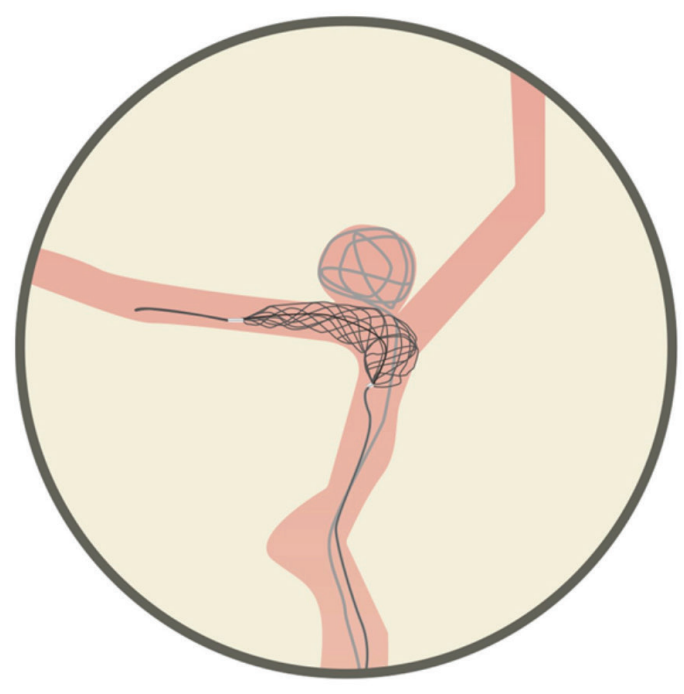

a.

Figure 1. (a, b) The schematic diagram shows the (a) fluoro images of Comaneci device-assisted (arrowheads) coiling (arrow). After the coiling, the Comaneci device is pulled out

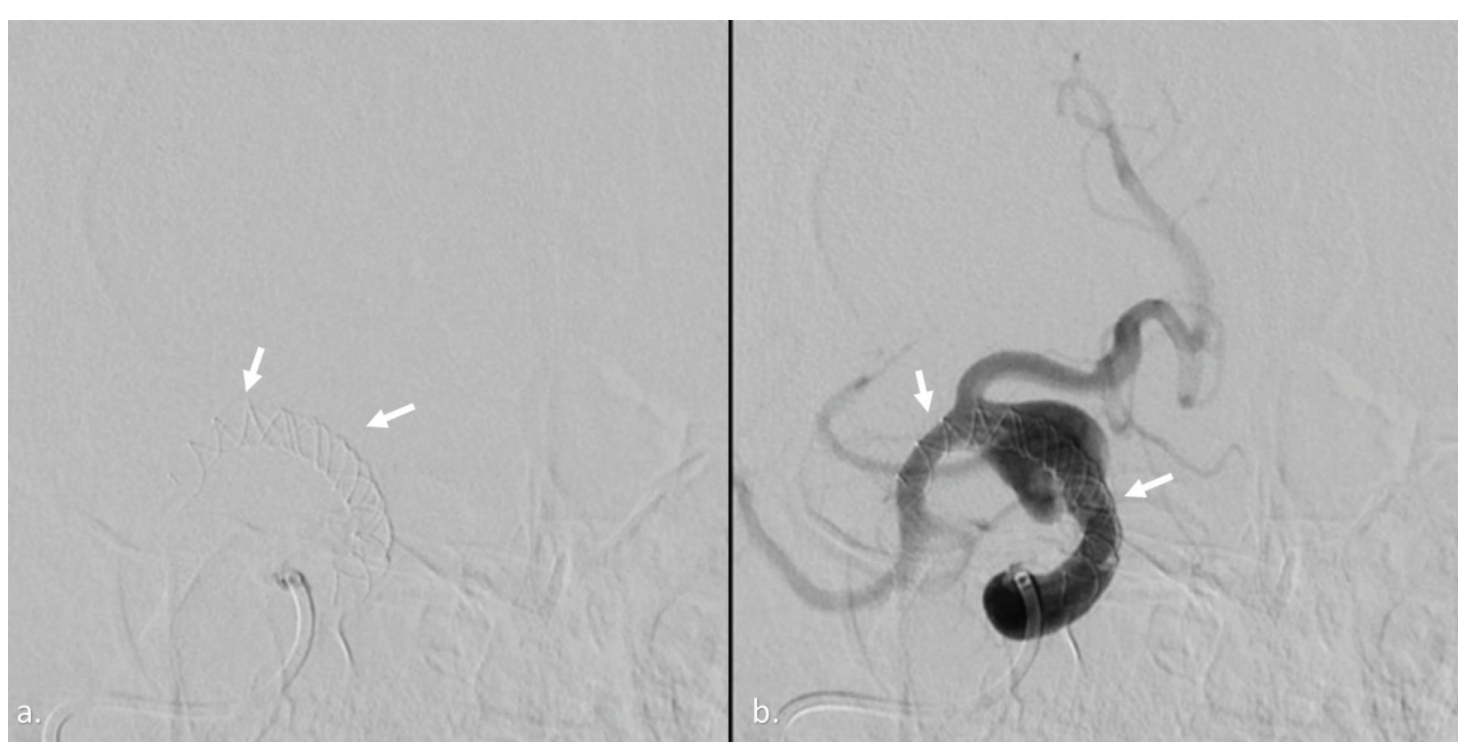

Figure 2. (a, b) The digital subtracted angiography images show the flow-diverter device (arrows) through the saccular aneurism

\section{Middle Meningeal Artery (MMA) Embolization}

MMA embolization has emerged as a promising treatment for chronic subdural hematoma (CSDH). CSDH incidence increase with increasing antiplatelet and anticoagulant use and the aging population (8). Spontaneous resolution of CSDH is rarely seen and mainly reported for patients with thrombotic thrombocytopenic purpura (9). Craniotomy or burr-hole irrigation and drainage are considered the gold standard for symptomatic CSDH. However, $5-30 \%$ of operative cases are associated with hematoma recurrence (10-15).

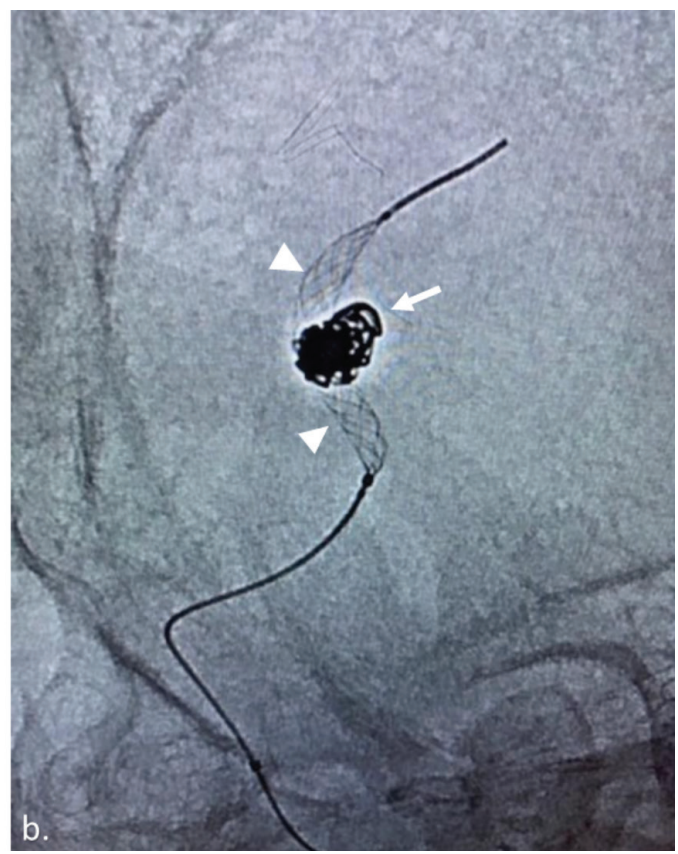


Repeated recurrence is potentially due to the failure of surgical evacuation alone to address the underlying pathophysiologic mechanism of CSDH formation, which involves the formation of fragile capillaries along the subdural membrane encapsulating the collection (16-18). Endovascular embolization of the MMA has been proposed as a minimally invasive method to permanently address the vascular supply of cSDH. Preliminary studies have evaluated the safety and efficacy of MMA embolization as a standalone procedure and in combination with surgical evacuation, with encouraging results (19) (Figure 3).

\section{Thyroid Ablation and Embolization}

Surgery is the primary therapeutic approach in benign and malign thyroid nodules; however, thermal ablation techniques and thyroid artery embolization procedures are the more recently used minimally invasive interventional radiological treatment options as a comparable alternative to the surgery in nodular thyroid diseases management (20-24). Moreover, recent studies showed that thermal ablation procedures are effective in papillary microcarcinoma of the thyroid gland $(23,25)$. As a comfortable treatment option, thermal ablation procedures started to also be frequently preferred by patients. Compared with surgical procedures, thermal ablation techniques appear as treatment methods that take a very short time, are easily applied and repeated, and most importantly, thyroid function-preserving treatment options (26). Additionally, thermal ablative procedures are the novel alternatives of radioactive iodine treatment in patients with autonomously functioning thyroid nodules (27). During patient follow-up, the greatest volume reduction is usually observed within the first month after ablation, followed by a more gradual decrease (28). Several sessions are needed, especially in patients suffering from cosmetic problems and patients with large nodules, to achieve complete ablation. Some complications, such as pain, voice chance, skin burn, hematoma, and thyroid function disorders, have been reported in the literature; however, most patients recovered without any permanent sequela $(28,29)$ (Figure 4).

\section{Cryoablation}

Cryoablation is one of the minimally invasive tumor ablation techniques, which is used in the daily practice of interventional radiology, especially for the liver, kidney, lungs, breast, and soft tissue masses (30-35). The specially designed ablation probes, which are called cryoprobes, are used during the procedure. The basic principle of the system refers to the use of thermal energy in low temperatures to achieve tumor cell destructions by freezing and thawing. This process occurred in different mechanisms, such as mechanical, osmotic, ischemic, and immunologic $(36,37)$. The most prominent advantage of cryoablation over other thermal ablation procedures, like radiofrequency (RF) or microwave (MW) ablation, is the real-time ablation zone observation, which is called an ice ball even in different radiological guidance. This issue would make the ablation session safer by avoiding nontarget ablation and minimizing complications. Contrarily, longer ablation time and smaller ablation zone are the main disadvantages of this technique compared to $\mathrm{MW}$ and RF ablations (38). Besides the most common complication after an ablation treatment due to the systemic response, which is a postablation syndrome, a more severe clinical condition, called cryoshock, that encompasses coagulopathy and multiorgan failure could rarely occur (39).

\section{Chemosaturation}

Besides primary tumors, the liver is among the organs with frequent metastasis (40). Surgical treatments, such as resection

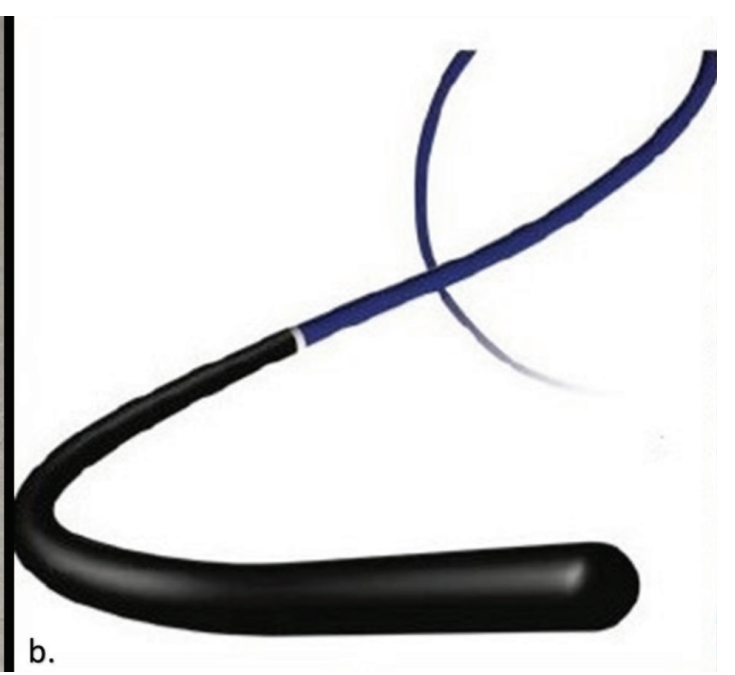

Figure 3. (a, b) One of the most common embolic materials is coils (a), which are deployed through small-size microcatheters (b) 


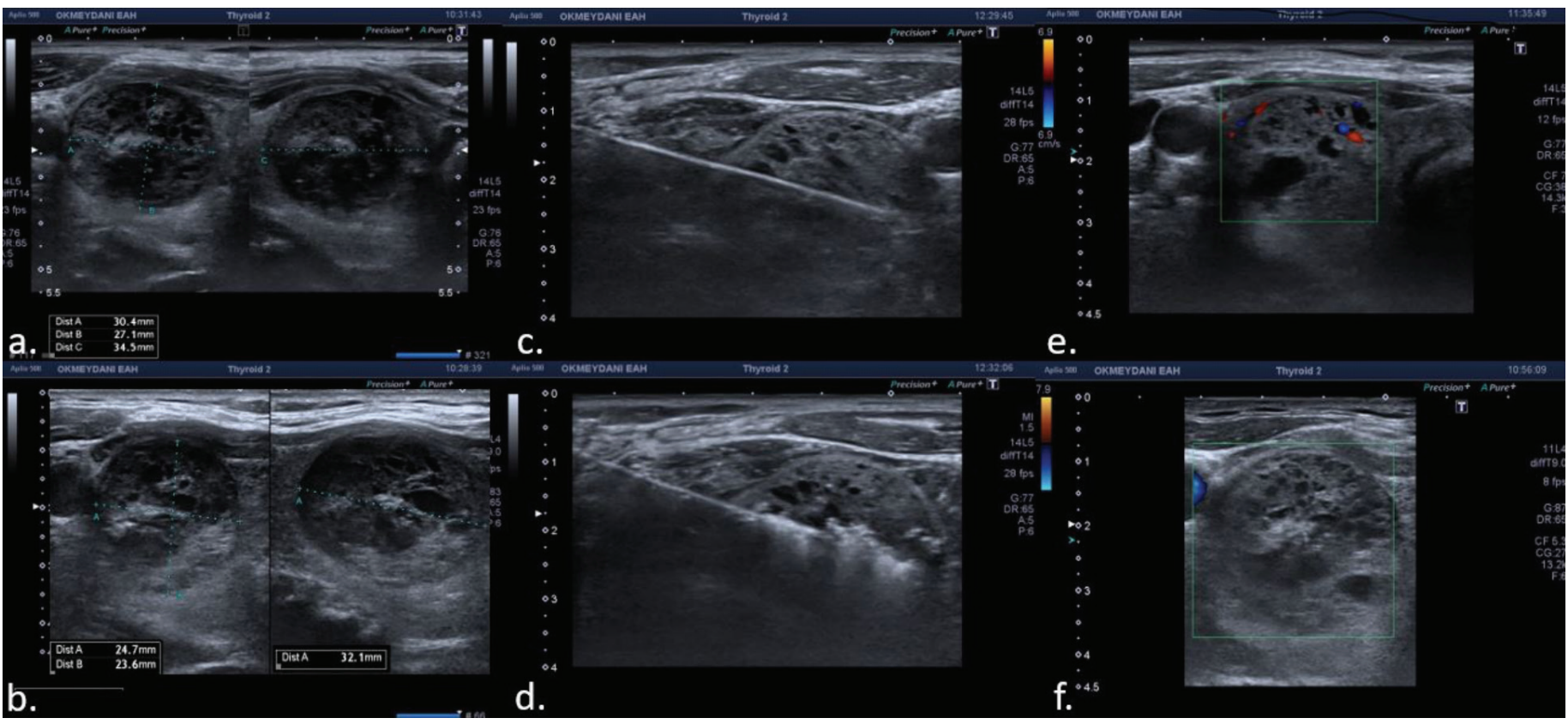

Figure 4. (a-f) Ultrasound-guided microwave ablation treatment of an autonomously functioning thyroid nodule (c-d). Compared to preprocedural volume (a), approximately 40 percent of reduction was achieved after the procedure (b). The Doppler signal on admission (e) was not seen anymore (f). The clinical conditions of the patient recovered and the thyroid functions were within normal limits

and transplantation, can be performed in primary and suitably metastatic tumors. Additionally, some interventional radiological procedures, such as local ablative and transarterial treatments, can be performed in patients who are not suitable for surgery and/or as part of combined treatments (40). Moreover, chemosaturation is another interventional radiological procedure for disease control, with prolonged survival, symptom palliation, and quality of life improvement in patients with primary liver tumors and liver metastases that cannot be surgically treated (40). This method aimed to expose the liver to the chemotherapeutic agent as intensely as possible, by delivering a high concentration of chemotherapeutic agent (melphalan) to the liver tissue through the arterial vascular inlet and taken out to the extracorporeal area by venous outlet before it reaches the systemic circulation. After the chemotherapeutic agent is cleared by the hemofiltration system, the blood flow is directed to the systemic circulation through second venous access. In this way, the liver tissue reaches intense chemotherapeutic concentrations in contrast to the very low concentrations in the systemic circulation (41). The effectiveness of chemosaturation has been demonstrated in the treatment of hepatocellular carcinoma, malignant melanoma metastasis, neuroendocrine tumor metastases, and cholangiocellular carcinoma that are not suitable for surgery and unresponsive to other treatments (4145). Some studies and case reports reported that stable disease was observed in some other metastatic tumor treatments $(41,44)$.
Patients with Child-Pugh B or C, proven portal hypertension, history of transient ischemic attack, left ventricular ejection fraction of $<50 \%$, bodyweight of $<35 \mathrm{~kg}$, history of gastrinoma, and those incompatible with general anesthesia constitutes the unsuitable group for the procedure, as well as general angiography contraindications (41). More studies are needed to compare the technique with other treatment options.

\section{Bariatric Embolization}

Obesity, which is common worldwide, is one of the important health problems that affect mortality and morbidity (46). The surgical approach is the standard treatment method in patients with obesity; however, transarterial embolization has become one of the alternative treatment options in selected patients. The method named bariatric arterial embolization in the literature is based on the catheterization of the left gastric and gastroepiploic arteries, accompanied by the main femoral artery access and the administration of embolic agents at these levels. The left gastric artery provides gastric fundus nutrition, thus reducing most of the ghrelin release from this level after embolization is theoretically planned (47). As a result of the decreased ghrelin level, weight loss is achieved in patients by reducing hunger at the hypothalamic level (48).

Studies are ongoing in the literature; however, significant results have been obtained according to the published preliminary reports of the GET LEAN study, in which patients' weight loss, 
quality of life, and appetite hormone levels are evaluated after 1-year follow-up (49). The preliminary results of the study conducted by Bai et al. (50) in China reported a significant decrease in subcutaneous fat tissue during follow-up in magnetic resonance imaging while providing safety and efficacy results that support other studies. In addition, the BEATLES study is still in progress and will be completed in 2023 as a randomized and placebo-controlled study that includes the 12-month follow-up results of the bodyweight changes in 59 patients in the study (51).

\section{Uterine Fibroid Embolization}

Most of the uterine fibroids, which constitute the most common uterine tumor in females of reproductive age, are asymptomatic and do not require treatment (52). Hysterectomy is a curative treatment method for the treatment of fibroids that cause mass effects and bleeding-related symptoms (52) but is not an appropriate treatment method for patients who consider having a child of reproductive age (53). Myomectomy is the uterine-sparing surgical method that can be applied in this patient group (53). As an alternative to these surgical treatments, uterine fibroid embolization, which is a minimally invasive interventional method together with percutaneous ablation, is a treatment method that includes the embolization of appropriate vessels that feeds the fibroid through the common femoral artery and from the bilateral uterine arteries and collateral pathways (54). Treatment indication includes patients with fibroid-related menometrorrhagia, pelvic pain, pelvic pressure sensation due to the mass effect of myoma, sudden urination, frequent urination, incontinence retention, and hydronephrosis (54). The procedure is contraindicated in patients with pregnancy and suspected pelvic gynecological malignancy, as well as general angiographic procedure contraindications. The procedure should not be preferred in patients who plan for pregnancy within 2 years, since patients who underwent myomectomy have a higher chance of pregnancy during this period $(53,54)$. Studies show that uterine fibroid embolization procedure treats symptoms that are related to menometrorrhagia and with mass effect at the same level as surgical treatments $(54,55)$. In addition, studies compared longterm results with surgery and revealed procedure effectiveness. Results of short and long-term studies (level A evidence level) revealed that uterine fibroid embolization is accepted as an effective and safe treatment method in selected patients who want to preserve their uterus $(52,54,56)$.

\section{Fallopian Tube Recanalization (FTR)}

FTR is the reopening of the fallopian tubes with the help of microcatheters and micro guidewires, which the interventional radiologist places into the vagina and cervix.
The microcatheter is inserted through the fallopian tube over a micro guidewire and clears any blockages in the fallopian tubes and restores the connection between the uterus and the abdominal cavity. This procedure is used to treat infertility caused by a blockage in the proximal fallopian tubes. Knowing the patient's menstrual cycle and ovulation timing is important to optimize pregnancy outcomes following FTR. FTR contraindications include active pelvic infection, pelvic malignancy, or pregnancy (57).

Technical success of FTR is noted in up to $100 \%$ of cases $(58,59)$, with the postprocedural re-occlusion rate of $20-50 \%$ (60). The pregnancy rate in 1-year following FTR is approximately $41 \%$, with the successful delivery of full-term infants in $84 \%$ of pregnancies (59). The global pregnancy and delivery rates for in vitro fertilization (IVF) are $24.0 \%$ and $17.6 \%$, respectively and for intracytoplasmic sperm injection (ICSI) is $26.2 \%$ and $19.0 \%$, respectively (61). Therefore, FTR should be considered and offered to patients who present with infertility secondary to proximal fallopian tube obstruction, particularly when they wish to pursue natural methods of conception before IVF or ICSI.

\section{Hemorrhoidal Embolization}

Hemorrhoidal disease is an important health problem that causes deterioration in the psychological and physical conditions of patients in the anorectal region. Today, most patients benefit from local treatments, but $10 \%$ of patients are treated with surgery (62). Endovascular hemorrhoidal embolization, called the emborrhoid technique in the literature, has emerged as a promising minimally invasive alternative method to surgical treatment (63). Clinical studies determined the main indication for emborrhoid method as patients with grade 1-3 bleeding hemorrhoids (64). The technique is performed by angiography after access from the patient's right main femoral artery, accompanied by the superior rectal artery that originates from the inferior mesenteric artery branch, and the medial rectal artery that commonly originates from the internal iliac artery. It involves embolizing agent injection by selecting those vessels. Medial rectal artery variation is seen in a wide range of $12-97 \%$ and may originate from the internal pudendal artery or the inferior gluteal artery. The classifications of rectal vascularity defined the types in which the medial rectal artery is dominant in arterial nutrition $(65,66)$. This anatomical variation significantly affects the success of embolization. Robust literature data were obtained for the safety and efficacy of the technique from 7 studies that are conducted with a total of 230 cases and between 2014 and 2021 (66). El Tawab et al. (67) reported 
anal pain in 27 (81\%) of 33 patients after embolization, with self-limited symptoms and no complications in the follow-up. The literature reported a clinical success range of $63-97 \%$. The important factors affecting clinical success are the variability in the defecation habits and diets of patients after the treatment and their compliance with the primary medical treatment.

The current data and the number of patients in studies are still very small; however, endovascular embolization is a promising treatment for patients with comorbidities who are not suitable for surgical treatment or with other primary pathology at the anorectal level compared with other surgical treatment methods (67).

\section{Treatment of Varicocele}

Varicocele, defined as dilatation and venous insufficiency in the pampiniform plexus, is a health problem seen in approximately $15 \%$ of the adult male population (68). Varicocele, which is the most common cause of male infertility, constitutes the cause in $30-40 \%$ of patients who are investigated for primary infertility that reaches $85 \%$ in the patient group presenting with secondary infertility. Various surgical methods can be used in varicocele treatment (68). Varicocele embolization is an alternative procedure to surgery, in which the gonadal veins are reached via the main femoral vein or the internal jugular vein and incompetent vein embolization is performed using various embolizing agents (69). Varicocele embolization was initially a treatment method used in patients with recurrent varicoceles after surgery or those with spermiograms that did not improve in the third month after surgery; however, it has now become the primary treatment method for varicocele (54). Patients with testicular pain and edema, varicocele-induced infertility, postoperative recurrent varicocele, and testicular atrophy in the pediatric population are suitable for the procedure (70). Numerous studies showed that varicocele embolization is a more comfortable and minimally invasive interventional method that improves spermiogram pain and increases pregnancy rates, with lower complications and faster recovery time (68-70).

\section{Prostatic Artery Embolization (PAE)}

PAE is a technique that results in prostatic artery occlusion, which most commonly originates from a branch of the internal iliac artery using particular embolic agents, such as polyvinyl acetate or microspheres. Due to ischemia in the prostate, apoptosis is triggered in the glandular cells that shrink/soften the prostate gland associated with the improvement of lower urinary tract symptoms (LUTS). Moreover, decreased density of a-1 adrenergic receptors by cell death leads to relaxation of smooth muscles that contribute to clinical improvement (71). Patients who cannot tolerate or with failed medical treatment can have PAE, especially, patients with very large prostate volume $\left(>100 \mathrm{~cm}^{3}\right)$, multi-comorbidities, prostatic hemorrhage, and indwelling foley catheters.

PAE is a minimally invasive procedure and is performed on an outpatient basis. Patients return to normal activities in a shorter period and complication rates are fewer in PAE compared to surgical methods. In addition, erectile and ejaculatory dysfunctions are less frequently seen (72). Compared with surgical methods, LUTS reduction is similar in PAE; however, improvements in peak flow rate, post-void residual volume, and prostate volume are less. PAE is recommended as a safe and acceptable minimally invasive treatment for appropriately selected patients using the Society of Interventional Radiology (SIR) guidelines (73). Further, SIR recommends PAE as a treatment option for patients with large prostate volume $\left(>100 \mathrm{~cm}^{3}\right)$ and acute or chronic urinary retention.

\section{Geniculate Artery Embolization (GAE)}

GAE is a new procedure that is performed in mild and moderate knee osteoarthritis (OA) refractory to the medical treatment for pain management. In this procedure, genicular arteries in the knee region, where patients mostly suffer pain, are determined by digital subtraction angiography and are embolized by using embolic agents like particles, polyvinyl alcohol, or imipenem/ cilastatin. Many studies were reported to understand the mechanism of knee pain in OA. The most important theory is inflammatory mediator-associated neurosensitization. Increased sensory nerves and neoangiogenesis caused by inflammatory mediators, which are released from the affected knee, play an important role in this mechanism. As microtrauma and inflammation persist, sensorial nerves are easily activated (74). Consequently, patients suffer from pain in minimal movement or even at rest. In GAE, pain control is expected by embolizing those neoangiogenic vessels. GAE is indicated in patients who are non-responsive to medical treatments and minimally invasive procedures, such as intraarticular glucocorticoid/hyaluronic acid injections. These minimally invasive procedures can provide short-term pain relief. Therefore, GAE can be offered to these patients as an alternative treatment before surgery.

A recent meta-analysis that included 11 studies with a median follow-up time of 6-12 months analyzed the visual analog score (VAS) and Western Ontario and McMaster Universities Osteoarthritis Index (WOMAC) scores (75). Statistically, significant decreases are reported in both VAS and WOMAC scores starting from 1 to 12 months after GAE. Very few studies reported 
minor complications according to the SIR guidelines and no studies showed major complications. Likewise, a statistically significant decrease in the need for pain medications (opioids and non-steroid anti-inflammatory drugs) is reported in these studies. A recent randomized controlled trial (RCT) compared the effectiveness of GAE to placebo (76) and reported a statistically significant decrease in both VAS and WOMAC scores in patients who underwent GAE procedure, without any improvement in pain scores in the placebo group. RCTs on the safety and effectiveness of GAE are ongoing and, undoubtingly, GAE has great potential in the management of moderate $\mathrm{OA}$.

\section{Ethics}

Peer-review: Internally peer-reviewed.

\section{Authorship Contributions}

Concept: H.Ö., S.A., O.I., E.K., T.K., J.G., Design: H.Ö., S.A., O.I., E.K., T.K., J.G., Data Collection or Processing: H.Ö., S.A., O.I., E.K., T.K., J.G., Analysis or Interpretation: H.Ö., S.A., O.I., E.K., T.K., J.G., Literature Search: H.Ö., S.A., O.I., E.K., T.K., J.G., Writing: H.Ö., S.A., O.I., E.K., T.K., J.G.

Conflict of Interest: No conflict of interest was declared by the authors.

Financial Disclosure: The authors declared that this study received no financial support.

\section{REFERENCES}

1. Bhogal P, Udani S, Cognard C, Piotin M, Brouwer P, Sourour NA, et al. Endosaccular flow disruption: where are we now? J Neurointerv Surg 2019;11:1024-5.

2. Oushy S, Rinaldo L, Brinjikji W, Cloft H, Lanzino G. Recent advances in stent-assisted coiling of cerebral aneurysms. Expert Rev Med Devices 2020;17:519-32.

3. Samaniego EA, Mendez AA, Nguyen TN, Kalousek V, Guerrero WR, Dandapat S, et al. LVIS Jr device for Y-stent-assisted coil embolization of wide-neck intracranial aneurysms: a multicenter experience. Interv Neurol 2018;7:271-83.

4. Ciccio G, Robert T, Smajda S, Fahed R, Desilles JP, Redjem H, et al. Double stent assisted coiling of intracranial bifurcation aneurysms in $Y$ and $X$ configurations with the Neuroform ATLAS stent: immediate and mid term angiographic and clinical follow-up. J Neurointerv Surg 2019;11:1239-42.

5. Kara B, Selcuk H, Kilinc F, Cakir C, Zalov H. Combination of temporary bridging device (Comaneci) and permanent stenting in the treatment of unruptured wide neck bifurcation aneurysms. Neuroradiology 2021;63:975-80.

6. Briganti F, Leone G, Marseglia M, Mariniello G, Caranci F, Brunetti A, et al. Endovascular treatment of cerebral aneurysms using flow-diverter devices: a systematic review. Neuroradiol J 2015;28:365-75.

7. Dandapat S, Mendez-Ruiz A, Martínez-Galdámez M, Macho J, Derakhshani S, Foa Torres G, et al. Review of current intracranial aneurysm flow diversion technology and clinical use. J Neurointerv Surg 2021;13:54-62

8. Matsumoto H, Hanayama H, Okada T, Sakurai Y, Minami H, Masuda A, et al. Clinical investigation of chronic subdural hematoma with impending brain herniation on arrival. Neurosurg Rev 2018;41:447-55.

9. Seçkin H, Kazanci A, Yigitkanli K, Simsek S, Kars HZ. Chronic subdural hematoma in patients with idiopathic thrombocytopenic purpura: A case report and review of the literature. Surg Neurol 2006;66:411-4; discussion 414

10. Amirjamshidi A, Abouzari M, Eftekhar B, Rashidi A, Rezaii J, Esfandiari K, et al. Outcomes and recurrence rates in chronic subdural haematoma. $\mathrm{Br}$ J Neurosurg 2007;21:272-5.

11. Jung YG, Jung NY, Kim E. Independent predictors for recurrence of chronic subdural hematoma. J Korean Neurosurg Soc 2015;57:266-70.

12. Torihashi K, Sadamasa N, Yoshida K, Narumi O, Chin M, Yamagata S. Independent predictors for recurrence of chronic subdural hematoma: a review of 343 consecutive surgical cases. Neurosurgery 2008;63:11259; discussion 1129.

13. Leroy HA, Aboukaïs R, Reyns N, Bourgeois P, Labreuche J, Duhamel $A$, et al. Predictors of functional outcomes and recurrence of chronic subdural hematomas. J Clin Neurosci 2015;22:1895-900.

14. Oh HJ, Lee KS, Shim JJ, Yoon SM, Yun IG, Bae HG. Postoperative course and recurrence of chronic subdural hematoma. J Korean Neurosurg Soc 2010;48:518-23.

15. Santarius T, Kirkpatrick PJ, Ganesan D, Chia HL, Jalloh I, Smielewski $P$, et al. Use of drains versus no drains after burr-hole evacuation of chronic subdural haematoma: a randomised controlled trial. Lancet 2009;374:1067-73.

16. Santarius T, Kirkpatrick PJ, Kolias AG, Hutchinson PJ. Working toward rational and evidence-based treatment of chronic subdural hematoma. Clin Neurosurg 2010;57:112-22.

17. Stanisic M, Aasen AO, Pripp AH, Lindegaard KF, Ramm-Pettersen J, Lyngstadaas SP, et al. Local and systemic pro-inflammatory and antiinflammatory cytokine patterns in patients with chronic subdural hematoma: a prospective study. Inflamm Res 2012;61:845-52.

18. Kalamatianos T, Stavrinou LC, Koutsarnakis C, Psachoulia C, Sakas DE, Stranjalis G. PIGF and sVEGFR-1 in chronic subdural hematoma: implications for hematoma development. J Neurosurg 2013;118:353-7.

19. Ban SP, Hwang G, Byoun HS, Kim T, Lee SU, Bang JS, et al. Middle meningeal artery embolization for chronic subdural hematoma. Radiology 2018;286:992-9.

20. Papini E, Pacella CM, Misischi I, Guglielmi R, Bizzarri G, Døssing H, et al. The advent of ultrasound-guided ablation techniques in nodular thyroid disease: towards a patient-tailored approach. Best Pract Res Clin Endocrinol Metab 2014;28:601-18.

21. Baek JH, Lee JH, Sung JY, Bae JI, Kim KT, Sim J, et al. Complications encountered in the treatment of benign thyroid nodules with US-guided radiofrequency ablation: a multicenter study. Radiology 2012;262:335-42.

22. Lim HK, Lee JH, Ha EJ, Sung JY, Kim JK, Baek JH. Radiofrequency ablation of benign non-functioning thyroid nodules: 4-year follow-up results for 111 patients. Eur Radiol 2013;23:1044-9.

23. Cui T, Jin C, Jiao D, Teng D, Sui G. Safety and efficacy of microwave ablation for benign thyroid nodules and papillary thyroid microcarcinomas: a systematic review and meta-analysis. Eur J Radiol 2019 Sep;118:58-64.

24. Yilmaz S, Habibi HA, Yildiz A, Altunbas H. Thyroid embolization for nonsurgical treatment of nodular goiter: a single-center experience in 56 consecutive patients. J Vasc Interv Radiol 2021;32:1449-56. 
25. Wu R, Luo Y, Tang J, Yang M, Li J, Zhang Y, et al. Ultrasound-guided radiofrequency ablation for papillary thyroid microcarcinoma: a retrospective analysis of 198 patients. Int J Hyperthermia 2020;37:16874.

26. Ji Hong M, Baek JH, Choi YJ, Lee JH, Lim HK, Shong YK, et al. Radiofrequency ablation is a thyroid function-preserving treatment for patients with bilateral benign thyroid nodules. J Vasc Interv Radiol 2015;26:55-61.

27. Sung JY, Baek JH, Jung SL, Kim JH, Kim KS, Lee D, et al. Radiofrequency ablation for autonomously functioning thyroid nodules: a multicenter study. Thyroid 2015;25:112-7.

28. Spiezia S, Garberoglio R, Milone F, Ramundo V, Caiazzo C, Assanti AP, et al. Thyroid nodules and related symptoms are stably controlled two years after radiofrequency thermal ablation. Thyroid 2009;19:219-25.

29. Kim YS, Rhim H, Tae K, Park DW, Kim ST. Radiofrequency ablation of benign cold thyroid nodules: initial clinical experience. Thyroid 2006;16:361-7.

30. Erinjeri JP, Clark TW. Cryoablation: mechanism of action and devices. J Vasc Interv Radiol 2010;21(Suppl 8):S187-91.

31. Crocetti L, de Baére T, Pereira PL, Tarantino FP. CIRSE standards of practice on thermal ablation of liver tumours. Cardiovasc Intervent Radiol 2020;43:951-62.

32. Krokidis ME, Orsi F, Katsanos K, Helmberger T, Adam A. CIRSE Guidelines on percutaneous ablation of small renal cell carcinoma. Cardiovasc Intervent Radiol 2017;40:177-91.

33. Venturini M, Cariati M, Marra P, Masala S, Pereira PL, Carrafiello G. CIRSE standards of practice on thermal ablation of primary and secondary lung tumours. Cardiovasc Intervent Radiol 2020;43:667-83.

34. Mauri G, Sconfienza LM, Pescatori LC, Fedeli MP, Alì M, Di Leo G, et al. Technical success, technique efficacy and complications of minimallyinvasive imaging-guided percutaneous ablation procedures of breast cancer: a systematic review and meta-analysis. Eur Radiol 2017;27:3199210.

35. Schmitz JJ, Schmit GD, Atwell TD, Callstrom MR, Kurup AN, Weisbrod AJ, et al. Percutaneous cryoablation of extraabdominal desmoid tumors: a 10-year experience. AJR Am J Roentgenol 2016;207:190-5.

36. Wiesmann UN, DiDonato S, Herschkowitz NN. Effect of chloroquine on cultured fibroblasts: release of lysosomal hydrolases and inhibition of their uptake. Biochem Biophys Res Commun 1975;66:1338-43.

37. Fraser J, Gill W. Observations on ultra-frozen tissue. Br J Surg 1967;54:7706 .

38. Zhou W, Herwald SE, McCarthy C, Uppot RN, Arellano RS. Radiofrequency ablation, cryoablation, and microwave ablation for T1a renal cell carcinoma: a comparative evaluation of therapeutic and renal function outcomes. J Vasc Interv Radiol 2019;30:1035-42.

39. Rong G, Bai W, Dong Z, Wang C, Lu Y, Zeng Z, et al. Long-term outcomes of percutaneous cryoablation for patients with hepatocellular carcinoma within Milan criteria. PLoS One 2015;10:e0123065.

40. Petrowsky H, Fritsch R, Guckenberger M, De Oliveira ML, Dutkowski P, Clavien PA. Modern therapeutic approaches for the treatment of malignant liver tumours. Nat Rev Gastroenterol Hepatol 2020;17:75572.

41. Vogel A, Gupta S, Zeile M, von Haken R, Brüning R, Lotz G, et al Chemosaturation percutaneous hepatic perfusion: a systematic review. Adv Ther 2017;33:2122-38.

42. Schönfeld L, Hinrichs JB, Marquardt S, Voigtländer T, Dewald C, Koppert $\mathrm{W}$, et al. Chemosaturation with percutaneous hepatic perfusion is effective in patients with ocular melanoma and cholangiocarcinoma. J Cancer Res Clin Oncol 2020;146:3003-12.

43. Makris GC, Efthymiou E, Little M, Boardman P, Anthony S, Uberoi R, et al. Safety and effectiveness of the different types of embolic materials for the treatment of testicular varicoceles: a systematic review. $\mathrm{Br} J$ Radiol 2018;91:20170445.

44. Marquardt S, Kirstein MM, Brüning R, Zeile M, Ferrucci PF, Prevoo $W$, et al. Percutaneous hepatic perfusion (chemosaturation) with melphalan in patients with intrahepatic cholangiocarcinoma: European multicentre study on safety, short-term effects and survival. Eur Radiol 2019;29:1882-92.

45. Veelken R, Maiwald B, Strocka S, Petersen TO, Moche M, Ebel S, et al. Repeated percutaneous hepatic perfusion with melphalan can maintain long-term response in patients with liver cancers. Cardiovasc Intervent Radiol 2021;1-5.

46. Au N, Johnston DW. Too much of a good thing? Exploring the Impact of wealth on weight. Health Econ 2015;24:1403-21.

47. Gunn AJ, Oklu R. A preliminary observation of weight loss following left gastric artery embolization in humans. J Obes 2014;2014:185349.

48. Kojima M, Hosoda H, Date Y, Nakazato M, Matsuo H, Kangawa K. Ghrelin is a growth-hormone-releasing acylated peptide from stomach. Nature 1999;402:656-60.

49. Syed MI, Morar K, Shaikh A, Craig P, Khan O, Patel S, et al. Gastric artery embolization trial for the lessening of appetite nonsurgically (GET LEAN): six-month preliminary data. J Vasc Interv Radiol 2016;27:1502-8.

50. Bai ZB, Qin YL, Deng G, Zhao GF, Zhong BY, Teng GJ. Bariatric embolization of the left gastric arteries for the treatment of obesity: 9-month data in 5 patients. Obes Surg 2018;28:907-15.

51. Weiss CR, Abiola GO, Fischman AM, Cheskin LJ, Vairavamurthy J, Holly $B$, et al. Bariatric embolization of arteries with imaging visible embolics (BEATLES) (BAE2). Available from: https://clinicaltrials.gov/ct2/show/ NCT04197336

52. Vilos GA, Allaire C, Laberge PY, Leyland N; Special Contributors, The management of uterine leiomyomas. J Obstet Gynaecol Can 2015;37:157-78.

53. Manyonda I, Belli AM, Lumsden MA, Lumsden MA, Moss J, McKinnon W, et al. Uterine-artery embolization or myomectomy for uterine fibroids. N Engl J Med 2020;383:440-51.

54. Krishna K. Handbook of interventional radiologic procedures. 5th ed Philadelphia, PA, USA. Wolter Kluwer, 2016:s.298-304.

55. Clements W, Ang WC, Law M, Goh GS. Treatment of symptomatic fibroid disease using uterine fibroid embolisation: an Australian perspective. Aust N Z J Obstet Gynaecol 2020;60:324-9.

56. de Bruijn AM, Ankum WM, Reekers JA, Birnie E, van der Kooij SM, Volkers NA, et al. Uterine artery embolization vs hysterectomy in the treatment of symptomatic uterine fibroids: 10-year outcomes from the randomized EMMY trial. Am J Obstet Gynecol 2016;215:745.e1-745.e12.

57. Kohi MP. Interventional radiologist's approach to fallopian tube recanalization. Tech Vasc Interv Radiol 2021;24:100736.

58. Thurmond AS, Machan LS, Maubon AJ, Rouanet JP, Hovsepian DM, Moore A, et al. A review of selective salpingography and fallopian tube catheterization. Radiographics 2000;20:1759-68.

59. Al-Omari M, Al-Mnayyis A, Obeidat N, Amarin Z, Zayed F, Rousan L, et al. Fallopian tube recanalisation using dedicated radiographic tubal assessment set in angiography suite. J Med Imaging Radiat Oncol 2014;58:415-21. 
60. Huang C, He X, Luo W, Chen H, Huang Y. Combined chitosan and Dan-shen injection for long-term tubal patency in fallopian tube recanalization for infertility. Drug Deliv Transl Res 2019;9:738-47.

61. Adamson GD, de Mouzon J, Chambers GM, Zegers-Hochschild F, Mansour $\mathrm{R}$, Ishihara $\mathrm{O}$, et al. International Committee for Monitoring Assisted Reproductive Technology: world report on assisted reproductive technology, 2011. Fertil Steril 2018;110:1067-80.

62. Rakinic J, Poola VP. Hemorrhoids and fistulas: new solutions to old problems. Curr Probl Surg 2014;51:98-137.

63. Vidal V, Louis G, Bartoli JM, Sielezneff I. Embolization of the hemorrhoidal arteries (the emborrhoid technique): a new concept and challenge for interventional radiology. Diagn Interv Imaging 2014;95:307-15.

64. Vidal V, Sapoval M, Sielezneff Y, De Parades V, Tradi F, Louis G, et al. Emborrhoid: a new concept for the treatment of hemorrhoids with arterial embolization: the first 14 cases. Cardiovasc Intervent Radiol 2015;38:72-8.

65. Bilhim T, Pisco JM, Rio Tinto H, Fernandes L, Pinheiro LC, Furtado A, et al. Prostatic arterial supply: anatomic and imaging findings relevant for selective arterial embolization. J Vasc Interv Radiol 2012;23:1403-15.

66. Zakharchenko A, Kaitoukov Y, Vinnik Y, Tradi F, Sapoval M, Sielezneff I, et al. Safety and efficacy of superior rectal artery embolization with particles and metallic coils for the treatment of hemorrhoids (Emborrhoid technique). Diagn Interv Imaging 2016;97:1079-84.

67. El Tawab KA, Salem AA, Khafagy R. New technique of embolization of the hemorrhoidal arteries using embolization particles alone: retrospective results in 33 patients. Arab J Interv Radiol 2020;4:27-31.

68. Johnson D, Sandlow J. Treatment of varicoceles: techniques and outcomes. Fertil Steril 2017;108:378-84.

69. Halpern J, Mittal S, Pereira K, Bhatia S, Ramasamy R. Percutaneous embolization of varicocele: technique, indications, relative contraindications, and complications. Asian J Androl 2016;18:234-8.
70. Broe MP, Ryan JPC, Ryan EJ, Murphy DJ, Mulvin DW, Cantwell C, et al. Spermatic vein embolization as a treatment for symptomatic varicocele. Can Urol Assoc J 2021;15:E569-73.

71. Sun F, Crisóstomo V, Báez-Díaz C, Sánchez FM. Prostatic artery embolization (PAE) for symptomatic benign prostatic hyperplasia (BPH): part 2, insights into the technical rationale. Cardiovasc Intervent Radiol 2016;39:161-9.

72. Dias US Jr, de Moura MRL, Viana PCC, de Assis AM, Marcelino ASZ, Moreira $\mathrm{AM}$, et al. Prostatic artery embolization: indications, preparation, techniques, imaging evaluation, reporting, and complications. Radiographics 2021;41:1509-30.

73. McWilliams JP, Bilhim TA, Carnevale FC, Bhatia S, Isaacson AJ, Bagla S, et al. Society of interventional radiology multisociety consensus position statement on prostatic artery embolization for treatment of lower urinary tract symptoms attributed to benign prostatic hyperplasia: from the society of interventional radiology, the cardiovascular and interventional radiological society of Europe, Société Française de Radiologie, and the British Society of Interventional radiology: endorsed by the Asia Pacific Society of Cardiovascular and interventional radiology, Canadian Association for Interventional Radiology, Chinese college of interventionalists, Interventional Radiology Society of Australasia, Japanese Society of Interventional Radiology, and Korean Society of Interventional Radiology. J Vasc Interv Radiol 2019;30:62737.e1.

74. Kidd B. Mechanisms of pain in osteoarthritis. HSS J 2012;8:26-8.

75. Torkian P, Golzarian J, Chalian M, Clayton A, Rahimi-Dehgolan S, Tabibian E, et al. Osteoarthritis-related knee pain treated with genicular artery embolization: a systematic review and meta-analysis. Orthop J Sports Med 2021;9:23259671211021356.

76. Bagla S, Piechowiak R, Sajan A, Orlando J, Hartman T, Isaacson A. Multicenter randomized sham controlled study of genicular artery embolization for knee pain secondary to osteoarthritis. J Vasc Interv Radiol 2021;:S1051-0443:01389-0. 